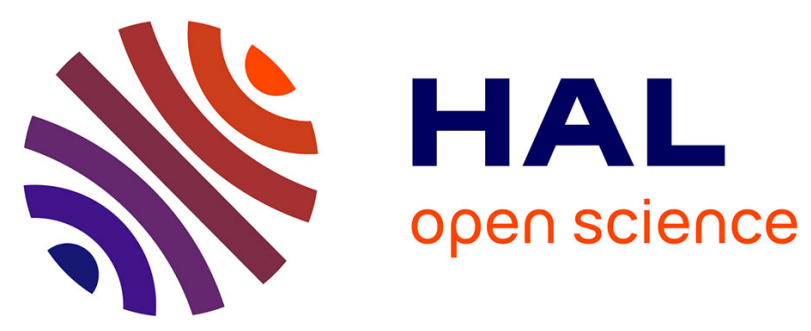

\title{
Transient UWB Antenna Near-Field and Far-Field Assessment From Time Domain Planar Near-Field Characterization: Simulation and Measurement Investigations
}

Mohammed Serhir

\section{To cite this version:}

Mohammed Serhir. Transient UWB Antenna Near-Field and Far-Field Assessment From Time Domain Planar Near-Field Characterization: Simulation and Measurement Investigations. IEEE Transactions on Antennas and Propagation, 2015, 63 (11), pp.4868-4876. 10.1109/TAP.2015.2480404. hal-01242850

\section{HAL Id: hal-01242850}

https://hal-centralesupelec.archives-ouvertes.fr/hal-01242850

Submitted on 14 Dec 2015

HAL is a multi-disciplinary open access archive for the deposit and dissemination of scientific research documents, whether they are published or not. The documents may come from teaching and research institutions in France or abroad, or from public or private research centers.
L'archive ouverte pluridisciplinaire HAL, est destinée au dépôt et à la diffusion de documents scientifiques de niveau recherche, publiés ou non, émanant des établissements d'enseignement et de recherche français ou étrangers, des laboratoires publics ou privés. 


\title{
Transient UWB Antenna Near-Field and Far- Field Assessment from Time-Domain Planar Near-Field Characterization: Simulation and Measurement Investigations
}

\author{
Mohammed Serhir, Member, IEEE
}

\begin{abstract}
In this paper we present the experimental validation of Time-Domain (TD) Near-Field to Near-Field (NFNF) and Near-Field to Far-Field (NFFF) transformations for UWB antenna transient characterization. The used computation schemes for near-field to near- or far-field transformations are based on the Green's function representation of the radiated field where NF and FF are directly calculated in the time domain. The first step of the validation process comprises the electromagnetic simulation results dedicated to evaluate the accuracy of NFFF and NFNF transformations. The second step uses near-field measurement data of a Vivaldi antenna to validate the developed computation schemes whereas the measurement and calibration procedures are fully described. The measured NF data using Supelec planar and cylindrical near-field facilities are also compared with the electromagnetic simulation transient results of the Vivaldi antenna.
\end{abstract}

Index Terms - Time domain, antenna measurement, near-field far-field transformation,

\section{INTRODUCTION}

$\mathrm{F}$ OR Ground Penetrating Radar applications we are interested in measuring the free space transient response of Ultra Wide Band (UWB) antennas composing the radar [1][2]. The duration of the transient response is of a crucial importance and the designers try to shorten the antenna free space impulse response while enlarging its frequency bandwidth of matched input impedance (S11<-10dB) [3]. More generally, GPR using UWB non-dispersive antennas provides easily interpretable radargrams [4][5].

UWB antennas transient characterization can be carried out using NF or FF techniques [6][7]. Based on the Huygens principle, the NF measurement techniques make use of the tangential components of electric or magnetic field collected over a scan surface in the vicinity of the AUT. Then, these measured data are transformed to calculate the electromagnetic field at different distances [8]. The NF measurements can be conducted in a small and low cost

Manuscript received February 19, 2015.

M. Serhir is with Laboratoire Genie electrique et electronique de Paris (GeePs) (UMR 8507 CentraleSupelec - CNRS - UPSud - UPMC) 11 rue Joliot-Curie - Plateau de Moulon 91192 Gif sur Yvette Cedex - France, (email: mohammed.serhir@centralesupelec.fr). anechoic chamber and by time-gating the measured data, one can filter out multiple reflections occurring during the measurement [9][10]. This allows the data accuracy enhancement especially for low frequency measurement in small anechoic chambers for which the absorption quality is unsatisfactory. The TD techniques permit also the radiation pattern measurement in non-anechoic environment as presented in [11-14]. They are well adapted for studying the parasitic electromagnetic radiation emitted from electronic devices for electromagnetic compatibility purposes [15].

Even the theoretical development of the NFNF and NFFF transformations are detailed in [6][16][17], the experimental utilization of TD NF techniques are less popular than the FD techniques. This is due to difficult experimental implementation combined with the drawback related to the computer time requirement, which could make unrealistic the application of the technique to cases of practical interest. The transient NF measurement systems use wideband and small probes with low interaction with the AUT [18]. Moreover, in NFNF and NFFF transformation schemes the measured Efield and its time derivative are involved in the calculation process. The accuracy of the NFNF and NFFF transformation results depends on the highest point of the chosen interpolation technique to keep working with the minimum number of measured data [19]. In this paper, we use the reconstruction formula to calculate and interpolate the E-field and its time derivative as well for NFNF and NFFF transformation schemes.

Here we aim at validating NFNF and NFFF transformations using the experimental measurement and the electromagnetic simulation software CST MWS [20]. An UWB Vivaldi antenna designed for Ground Penetrating Radar (GPR) is used for this purpose. The Vivaldi TD NF data are collected at different distances from the antenna. First, the NFFF transformation results are presented in order to outline the errors due to the measurement surface truncation. Second, we evaluate the accuracy of the NFNF calculation using different set of measured NF data collected at different distances from the AUT. Third, we present the experimental validation of the NFNF transformation scheme we have developed based on the Green's function representation. Our algorithms are applied to data obtained from the measurement of the Vivaldi antenna in 


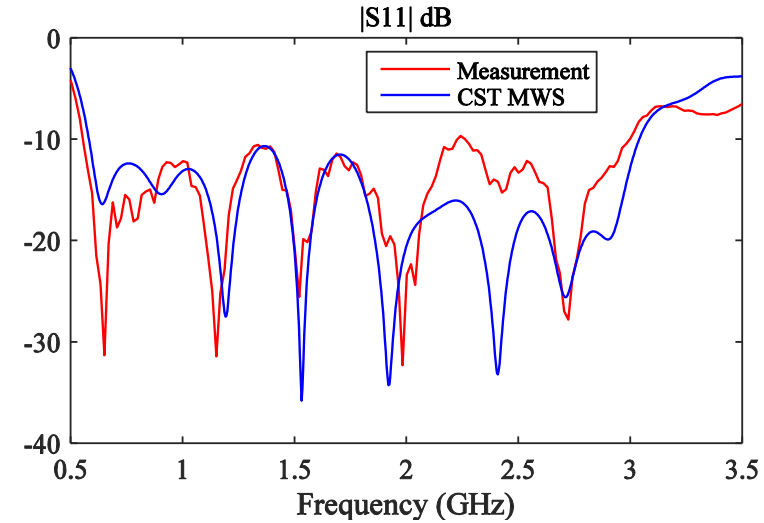

Fig. 1. The S11 of the Vivaldi antenna used for our transient analysis (optimized for the GPR application). This present the comparison between the S11 of the antenna modeled in the CST MWS and the measured one (fabricated antenna).

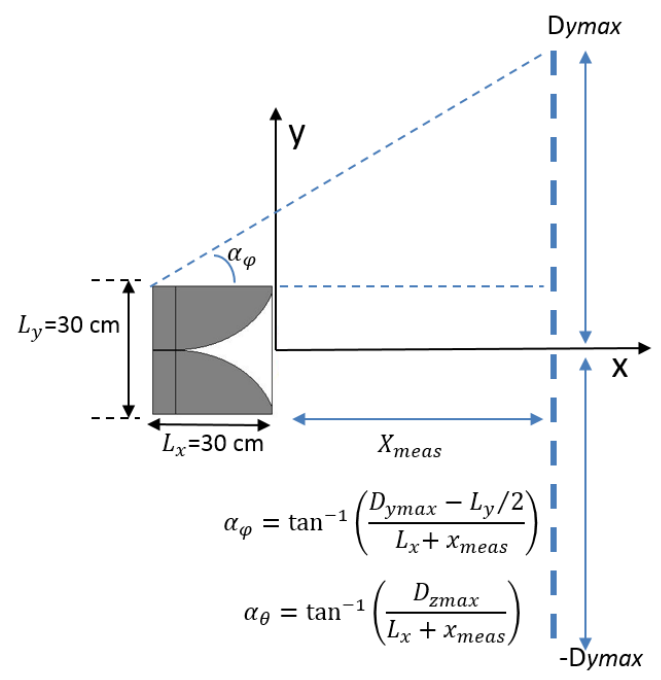

Fig. 2. Near-field measurement configuration at the distance $x_{\text {meas }}$ from the AUT. The tangential components Ey and Ez are regularly recorded over the scan surface in the zy plane. The far-field validity area is dependent on the angular domain described by $\alpha_{\theta}$ and $\alpha_{\varphi}$.

Supelec planar near-field measurement facility. Finally, the experimental validation aims also at comparing the simulation and measurement NF results.

This paper is structured as follows. In Section II, the planar NFNF and NFFF transformations formulations are described. In Section III, we present comparisons of FF and NF transformation results with the actual fields in the time domain using the simulation software CST MWS. Then, the measurement facilities used for our validation purpose are described and the NFNF transformation routine is validated using planar and cylindrical experimental setups in Section IV. Finally, concluding remarks are presented summarizing the relevance of our contribution in Section V. All theoretical formulations are expressed in the S.I. rationalized system with $e^{-i \omega t}$ time dependence.

\section{PLANAR NEAR-FIELD TRANSFORMATION FOR FORWARD PROPAGATION}

Let us consider UWB Vivaldi antenna. This is used to
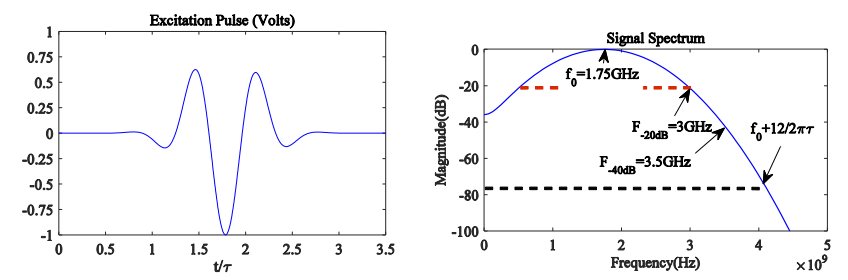

Fig. 3. The time domain excitation signal applied to the Vivaldi antenna (left). The excitation signal spectrum (right), the maximum of the signal spectrum is at $1.75 \mathrm{GHz}$
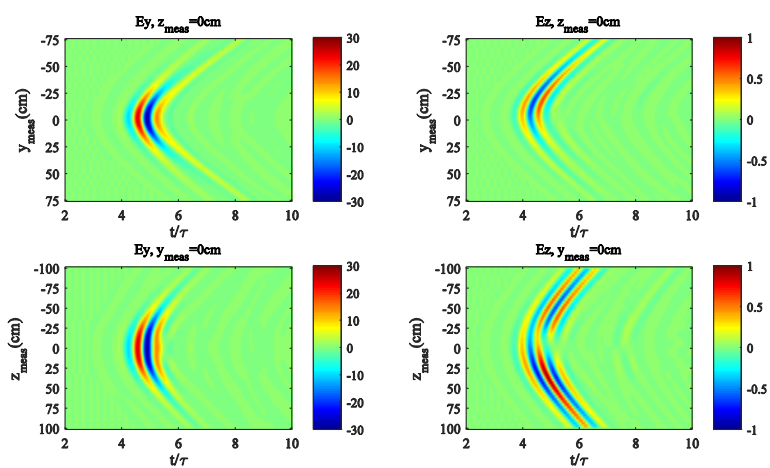

Fig. 4. The Vivaldi antenna $E y(V / m)$ and $E z(V / m)$ radiated near-field as a function of the time at $\mathrm{x}_{\text {meas }}=30 \mathrm{~cm}$ for the plane cuts $\mathrm{z}_{\text {meas }}=0$ and $\mathrm{y}_{\text {meas }}=0$

validate NFNF and NFFF transformation algorithms. The antenna has been optimized for the frequency band $(0.5 \mathrm{GHz}$ $3 \mathrm{GHz}$ ) and its $\mathrm{S}_{11}$ is presented in Fig. 1. In this paper we have adopted the NFNF and NFFF transformation algorithms based on the Green's function representation where NF and FF are determined directly in the time-domain. This choice has been made to clearly distinguish our work from the NFNF or NFFF transformations based on modal expansions (plane wave expansion in the frequency domain) [15].

\section{A. Planar Near-Field to Near-Field transformation}

Using the NF tangential components measured over the planar surface at the distance $\mathrm{x}_{\text {meas }}$ from the AUT the NFNF transformation algorithm allows calculating the transient field at different distances in the half space $\mathrm{x} \geq \mathrm{x}_{\text {meas }}$. The NFNF transformation is expressed as [6, eq. (5.6)][16]

$$
\begin{aligned}
& \vec{E}(\vec{r}, t)=\frac{-1}{2 \pi} \int_{-\infty}^{+\infty} \int_{-\infty}^{+\infty} \vec{R} \times\left[\begin{array}{l}
\frac{1}{c R^{2}} \vec{x} \times \frac{\partial \vec{E}_{\text {meas }}}{\partial t}\left(\vec{r}_{0}, t-R / c\right) \\
+\frac{\vec{x} \times \vec{E}_{\text {meas }}\left(r_{0}, t-R / c\right)}{R^{3}}
\end{array}\right] d y d z, \text { for } x \geq x_{\text {meas }} . \\
& \approx \frac{-1}{2 \pi} \sum_{m=-N_{y}}^{N_{y}} \sum_{n=-N_{z}}^{N_{z}} \vec{R} \times\left[\begin{array}{l}
\frac{1}{c R^{2}} \vec{x} \times \frac{\partial \vec{E}_{\text {meas }}}{\partial t}\left(\vec{r}_{0 m n}, t-R / c\right) \\
+\frac{x \times \vec{E}_{\text {meas }}\left(\vec{r}_{\text {omn }}, t-R / c\right)}{R^{3}}
\end{array}\right] \Delta y_{0} \Delta z_{0},
\end{aligned}
$$

The calculated field $\vec{E}(\vec{r}, t)$ in the left side of (1) is expressed at the observation point $\vec{r}=x \vec{x}+y \vec{y}+z \vec{z}$ at the instant $\mathrm{t}$ as a function of field $\vec{E}_{\text {meas }}\left(\overrightarrow{r_{0 m n}}, t-R / c\right)$ and its time derivative $\partial \vec{E}_{\text {meas }}\left(\overrightarrow{r_{0 m n}}, t-R / c\right) / \partial t$. These are measured at the position $\vec{r}_{0 m n}=x_{\text {meas }} \vec{x}+m \Delta y_{0} \vec{y}+n \Delta z_{0} \vec{z}$ at the instant $t-R / c$ with 
$\vec{R}=\vec{r}-\overrightarrow{r_{0 m n}}, R=\left|\vec{r}-\overrightarrow{r_{0 m n}}\right|$ and $\mathrm{c}$ is the free space light velocity.

As presented in Fig. 2, the measurement surface is defined for $-D_{\text {ymax }} \leq y_{\text {meas }} \leq D_{\text {ymax }}$ and $-D_{\text {zmax }} \leq z_{\text {meas }} \leq D_{\text {zmax }}$. The NF is sampled regularly using the Nyquist criterion $\Delta t=\pi / \omega_{\max }$, $\Delta y_{0}=\Delta z_{0}=\pi c / \omega_{\max }$ with $\omega_{\max }$ being the maximum angular pulsation of the AUT excitation signal, $\mathrm{N}_{\mathrm{y}}=\mathrm{D}_{\mathrm{ymax}} / \Delta \mathrm{y}_{0}$ and $\mathrm{N}_{\mathrm{z}}=\mathrm{D}_{\mathrm{zmax}} / \Delta \mathrm{z}_{0}$.

From (1) the first step in NFNF transformation is the interpolation of the measured field $\vec{E}_{\text {meas }}\left(\vec{r}_{0 m n}, t\right)$ and its time derivative to set their values at the instant $t-R / c$. The accuracy of NFNF transformation depends on the chosen interpolation method. In our analysis, we use the reconstruction formula to interpolate and assess the time derivative of the measured field at $t-R / c$.

Let us consider NF data measured over the scan surface at $\mathrm{x}_{\text {meas }}$ from the AUT. This NF is a band limited function that can be accurately interpolated using the reconstruction formula. Namely, the field $\vec{E}\left(\vec{r}_{0 m n}, t\right)$ at the instant $t$ in the time window $t_{0} \leq t \leq t_{0}+\left(N_{t}-1\right) \Delta t$ is calculated using the field samples $\vec{E}\left(\vec{r}_{0 m n}, t_{0}+l \Delta t\right)$ with the cardinal series as follows [6][17]

$$
\begin{aligned}
& \vec{E}\left(\vec{r}_{0 m n}, t\right)=\sum_{l=0}^{N_{1}-1} \frac{\sin \left[\pi\left(\frac{t-t_{0}-l \Delta t}{\Delta t}\right)\right]}{\pi\left(\frac{t-t_{0}-l \Delta t}{\Delta t}\right)} \vec{E}\left(\vec{r}_{0 m n}, t_{0}+l \Delta t\right) \\
& =\sum_{l=0}^{N_{t}-1} h(t) \cdot \vec{E}\left(\vec{r}_{0 m n}, t_{0}+l \Delta t\right) \\
& \text { with , } h(t)=\sin c\left[\pi\left(\frac{t-t_{0}-l \Delta t}{\Delta t}\right)\right], \text { for } t_{0} \leq t \leq t_{0}+\left(N_{t}-1\right) \Delta t
\end{aligned}
$$

This means that in the time window $t_{0} \leq t \leq t_{0}+\left(N_{t}-1\right) \Delta t$ and provided the NF is sampled respecting the Nyquist criterion $\Delta t=\pi / \omega_{\max }$, the time derivative of the E-field is expressed as

$$
\begin{aligned}
& \left.\frac{\overrightarrow{\partial E}}{\partial t} \vec{r}_{0 m n}, t\right)=\sum_{l=0}^{N_{t}-1} \frac{\partial h(t)}{\partial t} \vec{E}\left(\vec{r}_{0 m n}, t_{0}+l \Delta t\right) \\
& \text { with } \frac{\partial h}{\partial t}(t)=\frac{1}{t-\left(t_{0}+l \Delta t\right)}\left[\cos \left(\pi \frac{t-\left(t_{0}+l \Delta t\right)}{\Delta t}\right)-h(t)\right]
\end{aligned}
$$

In our analysis we use (2) and (3) to calculate the E-field and its time derivative between time-samples (at $t-R / c$ ) provided the sampling Nyquist criterion is respected. This criterion, which is linked to spatial NF sampling $\Delta \mathrm{y}_{0}=\Delta \mathrm{z}_{0}=$ $\mathrm{c} \Delta \mathrm{t}$, is sufficient to accurately perform the NFNF transformation.

\section{B. Planar Near-Field to Far-Field transformation}

The time domain NFFF transformation is formulated as $[6$, eq. (5.57)][16][17]

$$
\begin{aligned}
& \vec{E}_{F F}(\theta, \varphi, t)=\frac{-1}{2 \pi c} \int_{-\infty}^{+\infty} \int_{-\infty}^{+\infty} \overrightarrow{e_{r}} \times\left[\vec{x} \times \frac{\partial \vec{E}_{\text {meas }}}{\partial t}\left(\vec{r}_{0}, t+\vec{e}_{r} \cdot \vec{r}_{0} / c\right)\right] d y d z, \text { for } x \geq x_{\text {meas }} \\
& \approx \frac{-1}{2 \pi c} \sum_{m=-N_{y}}^{N y} \sum_{n=-N_{z}}^{N z} \overrightarrow{e_{r}} \times\left[\vec{x} \times \frac{\partial \vec{E}_{\text {mas }}}{\partial t}\left(\vec{r}_{0 m n}, t+\vec{e}_{r} \cdot \vec{r}_{0 m n} / c\right)\right] \Delta y_{0} \Delta z_{0}
\end{aligned}
$$

The antenna radiation pattern at the far-field distance $\vec{E}_{F F}(\theta, \varphi, t)$ in the direction $(\theta, \varphi)$ is written as a function of the time derivative of the tangential measured NF $\partial \vec{E}_{\text {meas }} / \partial t$. The spherical coordinates $(\theta, \varphi)$ are associated with the planar coordinates $\quad$ system $\quad(\mathrm{x}, \quad \mathrm{y}, \quad \mathrm{z}), \quad \overrightarrow{e_{r}}=\vec{r} /|r|=\cos \varphi \sin \theta \vec{x}$ $+\sin \varphi \sin \theta \vec{y}+\cos \theta \vec{z}$ is the FF observation direction and the measured field data $\vec{E}_{\text {meas }}$ are collected at $\vec{r}_{0}\left(x_{\text {meas }}, y_{\text {meas }}, z_{\text {meas }}\right)$. As expressed in (4), the infinite integration is truncated and we implicitly suppose that the field is weak beyond the measurement surface edges. However, one of the advantages of time-domain near-field measurements is that one can obtain exact early-time far-field pattern values even though the field outside the scanned area is strong.

In the next sections, we present the validation results of the NFNF and NFFF transformation using simulation and measurement results and the E-field time derivative calculated using (3).

\section{Electromagnetic Simulation Results}

We have developed a routine expressing (4) to study the NFFF transformation results when using different NF data collected at different measurement planes $\mathrm{x}_{\text {meas }}$.The Vivaldi antenna has been simulated using the transient simulator of the CST MWS to provide the NF data. The AUT is excited using a cosinusoidal voltage modulated by Gaussian signal to cover the AUT frequency band $(0.5 \mathrm{GHz}-3.5 \mathrm{GHz})$, $e(t)=-\cos \left(\omega_{0}\left(t-t_{0}\right)\right) e^{-4\left(t-t_{0}\right)^{2} / \tau^{2}}$ with $\omega_{0}=2 \pi \mathrm{f}_{0}, \mathrm{f}_{0}=1.75 \mathrm{GHz}$, $\tau=0.8 .10^{-9} \mathrm{~s}$ and the delay $\mathrm{t}_{0}=1.75 \tau$. The excitation signal and its spectrum normalized at $\mathrm{f}_{0}=1.75 \mathrm{GHz}$ are presented in Fig. 3.

The antenna TD NF is collected over the plane $\mathrm{x}=\mathrm{x}_{\text {meas }}$ respecting regularly spaced positions $\Delta \mathrm{y}_{0}$ and $\Delta \mathrm{z}_{0}$. Based on [6] the bandwidth of the Gaussian signal is approximately equal to $12 / 2 \pi \tau$. One can sample without any loss of information the radiated field respecting the Nyquist criterion $\Delta \mathrm{y}_{0}=\Delta \mathrm{z}_{0}=\lambda_{\min } / 2$, where $\lambda_{\min }=\mathrm{c} / \mathrm{f}_{\max }$, and $\mathrm{f}_{\max }$ is the maximum frequency expressed as $\mathrm{f}_{\max }=\mathrm{f}_{0}+12 / 2 \pi \tau=4.14$ GHz. 

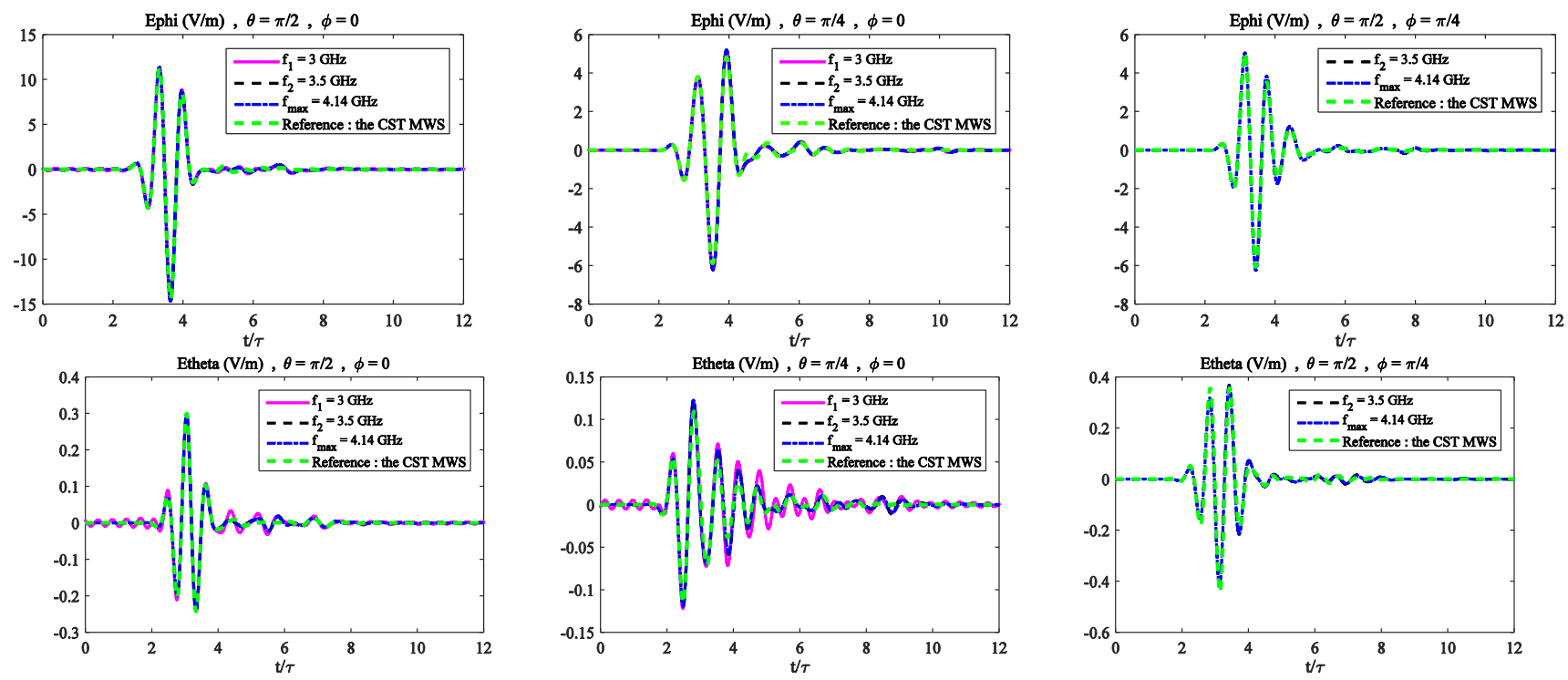

Fig. 5. The transient Etheta $(\mathrm{V} / \mathrm{m})$ and Ephi $(\mathrm{V} / \mathrm{m})$ far-field radiation pattern comparison considering different sampling frequencies for the spatial directions: $(\theta=$ $\pi / 2, \varphi=0),(\theta=\pi / 4, \varphi=0)$ and $(\theta=\pi / 2, \varphi=\pi / 4)$. The NF data are collected at $x_{\text {meas }}=30 \mathrm{~cm}$.
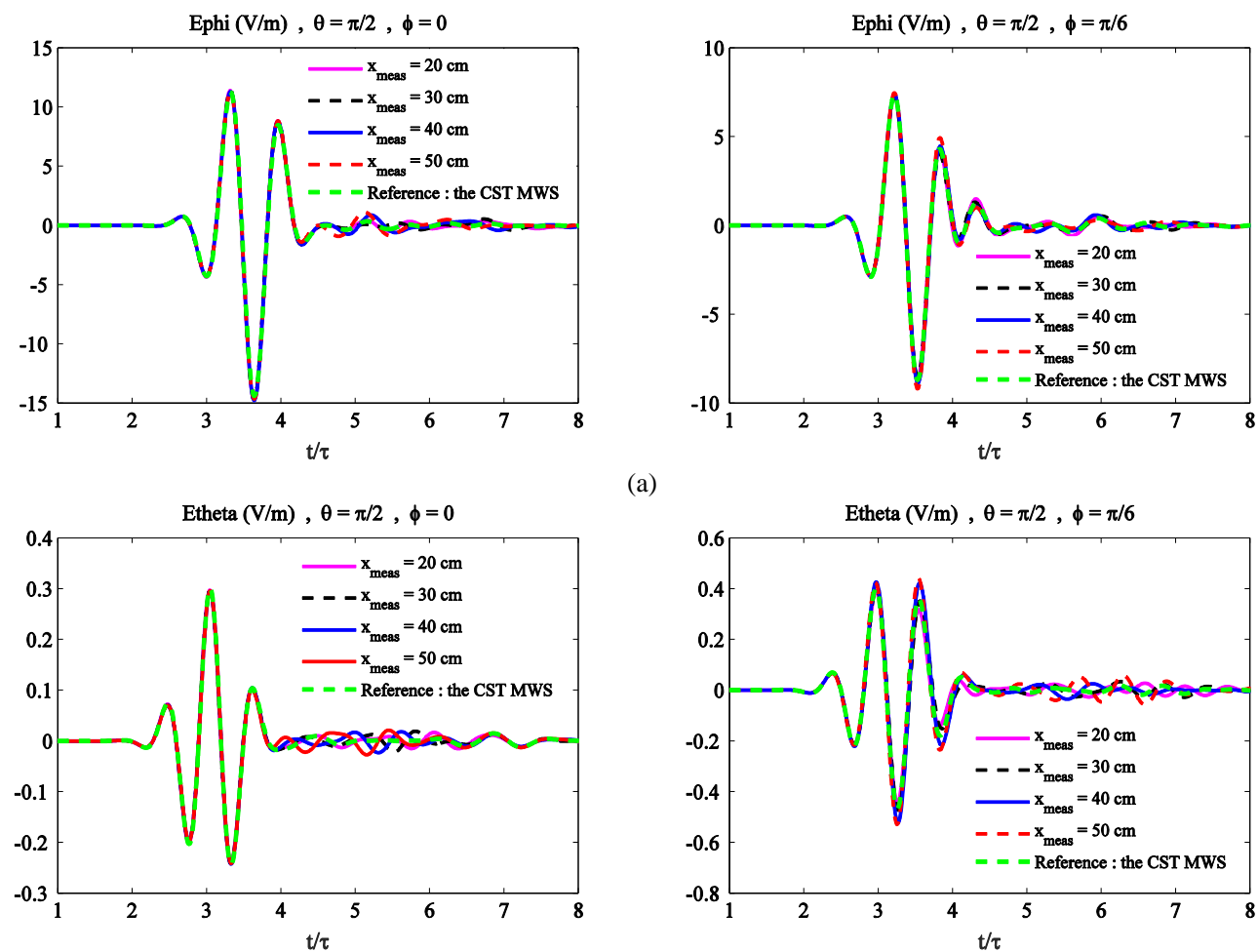

(a)

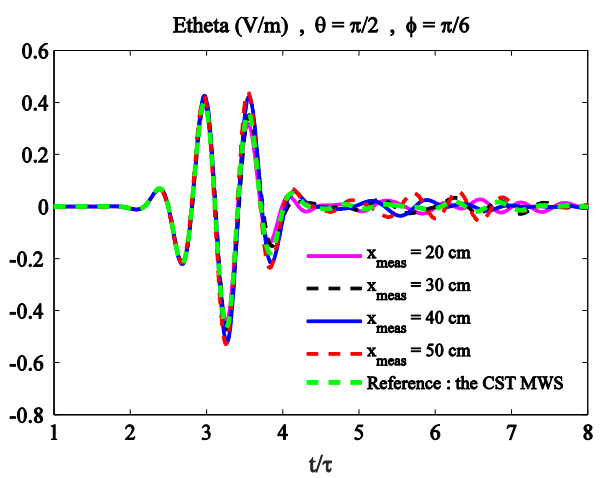

(b)

Fig. 6. The transient Etheta $(\mathrm{V} / \mathrm{m})$ and Ephi $(\mathrm{V} / \mathrm{m})$ far-field radiation pattern comparison considering different $\mathrm{NF}$ measurement distances $(20 \mathrm{~cm}, 30 \mathrm{~cm} 40 \mathrm{~cm}, 50$ cm) for the spatial directions: (a) $\theta=\pi / 2, \varphi=0$, (b) $\theta=\pi / 2, \varphi=\pi / 6$

Using the CST MWS we generate the antenna transient radiated NF over the plane $x_{\text {meas }}=30 \mathrm{~cm}$. This scan surface is delimited by $D_{z \max }=100 \mathrm{~cm}$ and $D_{y \max }=75 \mathrm{~cm}$ as defined in Fig. 2 and the NF in the cut planes $y_{\text {meas }}=0$ and $z_{\text {meas }}=0$ are presented in Fig. 4 for Ey and Ez components. The Vivaldi antenna is linearly polarized and the E-field is predominantly radiated through the Ey component and the Ez component is negligible comparatively to Ey.

Since the $\mathrm{S}_{11}$ (Fig. 1) of the Vivaldi antenna demonstrates a pass-band behavior $(0.5 \mathrm{GHz}-3 \mathrm{GHz})$, we are interested in evaluating the accuracy of the NFFF transformation as a function of the NF sampling frequency. To do so, we compare the actual FF obtained from the CST MWS with the NFFF transformation results using 3 different $\mathrm{NF}$ sampling frequencies $\mathrm{f}_{1}=3 \mathrm{GHz}, \mathrm{f}_{2}=3.5 \mathrm{GHz}, \mathrm{f}_{\max }=4.14 \mathrm{GHz}$. In Figs. 5 we present the FF comparison at the observation directions $(\theta=\pi / 2, \varphi=0),(\theta=\pi / 4, \varphi=0)$ and $(\theta=\pi / 2, \varphi=$ $\pi / 4)$ for the FF components $E_{\text {theta }}$ and $E_{\text {phi. }}$. 

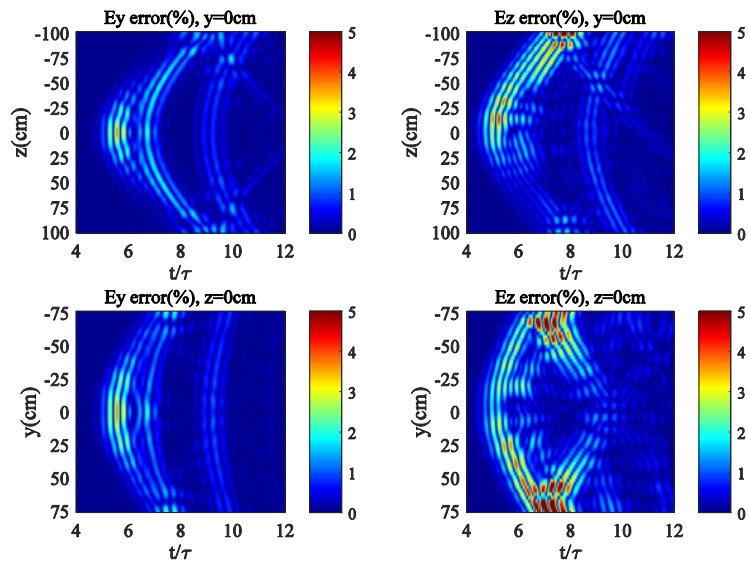

Fig. 7. The error values of Ey and Ez at the plane cuts $y=0$ and $z=0$ resulting from the NFNF transformation. The NF data is measured at $x_{\text {meas }}=$ $20 \mathrm{~cm}$ and transformed to calculate the transient field at $50 \mathrm{~cm}$ from the AUT.

As seen in Figs. 5 good agreements are noticed between the $\mathrm{E}_{\text {phi }}$ (co-polar) component of the actual $\mathrm{FF}$ and the ones resulting from NFFF transformations. The use of the sampling frequency $f_{1}=3 \mathrm{GHz}$ is responsible of the aliasing effects clearly seen for the cross-polarization component $\mathrm{E}_{\text {theta. }}$ In addition, the differences between the curves of Fig. 5 are due to measurement surface truncation. For the far-field observation point $(\theta=\pi / 2, \varphi=0)$ the difference between the actual FF and the calculated one starts at $\mathrm{t}=5.11 \tau$ that corresponds to the arrival time when the center of the pulse reached the measurement edge $D_{\text {ymax }}=75 \mathrm{~cm}$. The error corresponding to the measurement edge $D_{\text {zmax }}=100 \mathrm{~cm}$ is visible around $\mathrm{t}=6.10 \tau$.

Using the sampling frequency $\mathrm{f}_{\max }=4.14 \mathrm{GHz}$, we compare the NFFF results calculated from NF data collected at different planes $\mathrm{X}_{\text {meas }}=20 \mathrm{~cm}, 30 \mathrm{~cm}, 40 \mathrm{~cm}, 50 \mathrm{~cm}$. These calculated FF are compared in Figs. 6 with the actual one at the directions $(\theta=\pi / 2, \varphi=\pi / 6)$ and $(\theta=\pi / 3, \varphi=0)$. As presented in Figs. 6, good agreements are noticed for $2.5 \tau \leq \mathrm{t} \leq \mathrm{t}_{\mathrm{tr}}$, where $t_{\text {tr }}$ depends on the measurement distance $x_{\text {meas }}$ and the FF observation point $(\theta, \varphi)$. This effect is known as the truncation error and the FF reliable region is defined by $\alpha_{\theta}$ and $\alpha_{\varphi}$ expressed in Fig. 2 depends on the measurement distance.

Based on the presented simulation results, the developed NFFF transformation routine has been validated using the CST MWS. The NFFF transformation results have shown a satisfactory accuracy while using the Nyquist criterion for NF sampling.

The next comparisons aim at validating the TD NFNF transformation routine. For this, we provide tangential NF data at $\mathrm{x}_{\text {meas }}=20 \mathrm{~cm}$ for $-75 \mathrm{~cm} \leq \mathrm{y}_{\text {meas }} \leq 75 \mathrm{~cm}$ and $-100 \mathrm{~cm} \leq$ $\mathrm{z}_{\text {meas }} \leq 100 \mathrm{~cm}$ sampled using $\mathrm{f}_{\max }=4.14 \mathrm{GHz}$. Thereafter, we perform the NFNF transformation routine to calculate the field at $50 \mathrm{~cm}$ from the AUT. The NFNF transformation results $\left(\mathrm{E}_{\mathrm{NFtoNF}}\right)$ are compared with the actual NF $\left(\mathrm{E}_{\mathrm{ref}}\right)$ at the plane cuts ( $x=50 \mathrm{~cm}, y=0,-100 \mathrm{~cm} \leq z \leq 100 \mathrm{~cm})$ and $(x=50 \mathrm{~cm}$, $-75 \mathrm{~cm} \leq y \leq 75 \mathrm{~cm}, z=0)$ using the error expressed as:
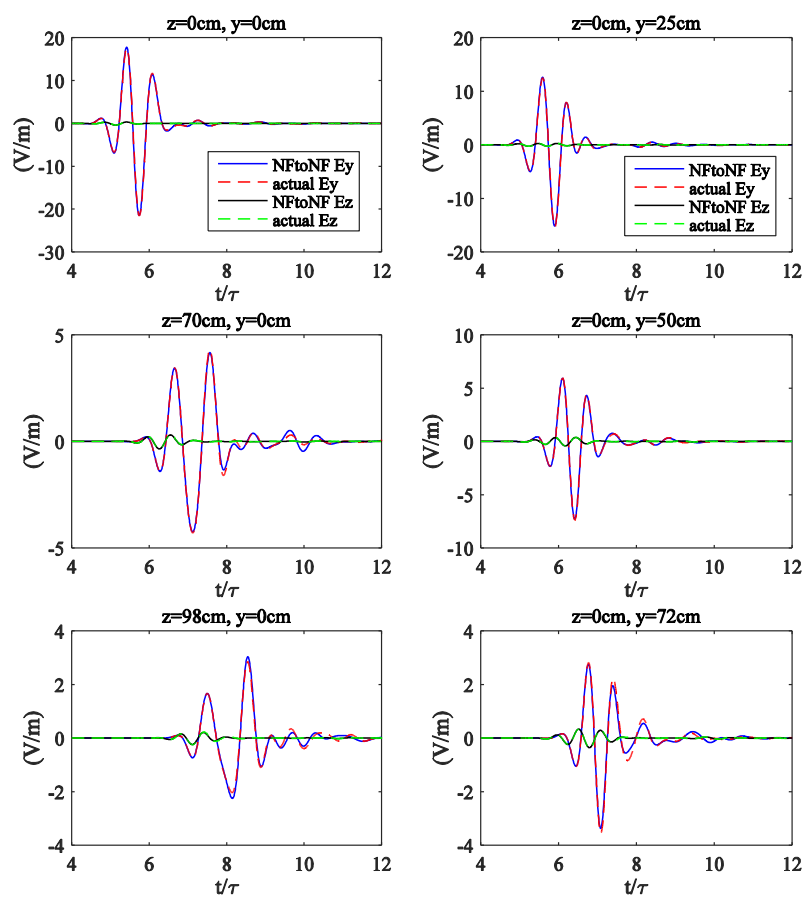

Fig. 8. The actual field comparison with transient $\mathrm{Ey}(\mathrm{V} / \mathrm{m})$ and $\mathrm{Ez}(\mathrm{V} / \mathrm{m})$ resulting from the NFNF transformation. The NF data is measured at $\mathrm{X}_{\text {meas }}=20 \mathrm{~cm}$ and transformed to calculate the antenna transient response at the spatial positions $\mathrm{A}(\mathrm{x}=50 \mathrm{~cm}, \mathrm{y}=0, \mathrm{z}=0), \mathrm{B}(50 \mathrm{~cm}, 25 \mathrm{~cm}, 0), \mathrm{C}(50 \mathrm{~cm}, 0,70$ $\mathrm{cm}), \mathrm{D}(50 \mathrm{~cm}, 50 \mathrm{~cm}, 0), \mathrm{E}(50 \mathrm{~cm}, 0,98 \mathrm{~cm})$ and $\mathrm{F}(50 \mathrm{~cm}, 72 \mathrm{~cm}, 0)$.

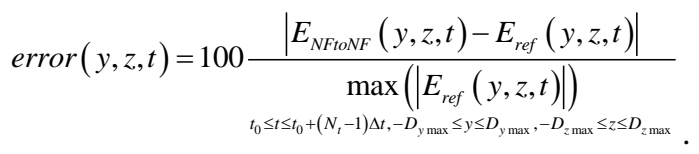

The error values are presented in Figs. 7 for the Ey and Ez components. As it is seen, the NFNF transformation errors are very low for the Ey components (co-polar) and reaches $5 \%$ at the edges of the measurement surface $(y= \pm 75 \mathrm{~cm}$ and $z=$ $\pm 100 \mathrm{~cm}$ ) for $\mathrm{Ez}$ component (cross-polar). These errors are due to NF measurement surface truncation. In Figs. 8, the calculated AUT transient radiated fields Ey and Ez are compared with the actual ones at different observation points $\mathrm{A}(x=50 \mathrm{~cm}, y=0, z=0), \mathrm{B}(50 \mathrm{~cm}, 25 \mathrm{~cm}, 0), \mathrm{C}(50 \mathrm{~cm}, 0,70$ $\mathrm{cm}), \mathrm{D}(50 \mathrm{~cm}, 50 \mathrm{~cm}, 0), \mathrm{E}(50 \mathrm{~cm}, 0,98 \mathrm{~cm})$ and $\mathrm{F}(50 \mathrm{~cm}, 72$ $\mathrm{cm}, 0)$. The calculated NF agrees very well with the actual one even for the observation points $\mathrm{E}$ and $\mathrm{F}$ situated in the area of the high error values (maximum 5\%) of Figs. 7.

To get a deep insight into the origin of the NFNF transformation errors we calculate the field at $x=50 \mathrm{~cm}$ from the AUT using NF data collected over the scan planes $\mathrm{x}_{\text {meas }}=$ $10 \mathrm{~cm}$ and $30 \mathrm{~cm}$. These are compared with the actual NF (the CST MWS) at the plane cuts $(x=50 \mathrm{~cm}, y=0,-100 \mathrm{~cm} \leq z \leq$ $100 \mathrm{~cm})$ and $(x=50 \mathrm{~cm},-75 \mathrm{~cm} \leq y \leq 75 \mathrm{~cm}, z=0)$. The resulting error values are presented in Figs. 9 (a) and (b). From Figs. 7 and Figs .9 we can conclude that the calculated results are completely unreliable outside of a certain spectral region. The erroneous ripples are due to the discontinuity of the measured field at the edge of the truncated surface. Hence, the 

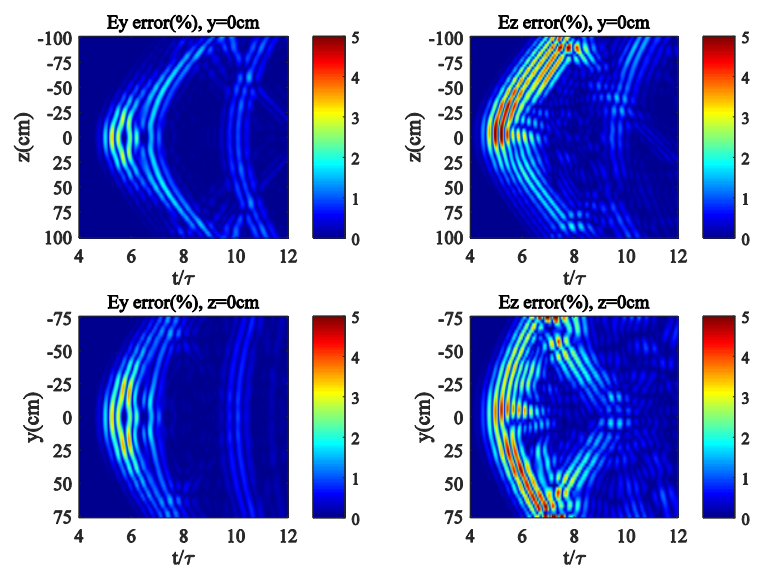

Fig. 9-a The error values of Ey and Ez at the plane cuts $y=0$ and $z=0$ resulting from the NFNF transformation: the NF data is measured at $\mathrm{x}_{\text {meas }}=10$ $\mathrm{cm}$ and transformed to calculate the field at $50 \mathrm{~cm}$ from the AUT

entire calculated pattern is always affected by errors, and it is not possible to define a region where the error is completely zero. However, the concept of the spectral reliable far-field region is usually applied to refer to the region in which the error is not negligible but is low [21].

From Figs. 7 and Figs. 9, the highest error value over the principal component Ey stay stable around 3\%. In Figs. 7 and Figs. 9 (a) corresponding to NF data collected at $x_{\text {meas }}=10 \mathrm{~cm}$ and $20 \mathrm{~cm}$, the truncation error is higher in the region $-50 \mathrm{~cm}$ $\leq \mathrm{y} \leq 50 \mathrm{~cm}$ and $-75 \mathrm{~cm} \leq \mathrm{z} \leq 75 \mathrm{~cm}$ in comparison with the results of $x_{\text {meas }}=30 \mathrm{~cm}$. The truncation error is directly linked to the level of the discontinuity of the measured field at the edge of the truncated surface. At $x_{\text {meas }}=10 \mathrm{~cm}$ and $20 \mathrm{~cm}$ this discontinuity is more important than for $\mathrm{x}_{\text {meas }}=30 \mathrm{~cm}$.

Up to now, we have studied the accuracy of NFFF and NFNF transformation routines using electromagnetic simulation software (the CST MWS). In the next section we describe the experimental validation of the developed transformation routines.

\section{MEASUREMENT Results}

The Vivaldi antenna used in the simulation presented above has been fabricated and Supelec planar NF range to measure its radiated field is presented in Fig. 10. The Vivaldi antenna and the measurement probe are placed inside the anechoic
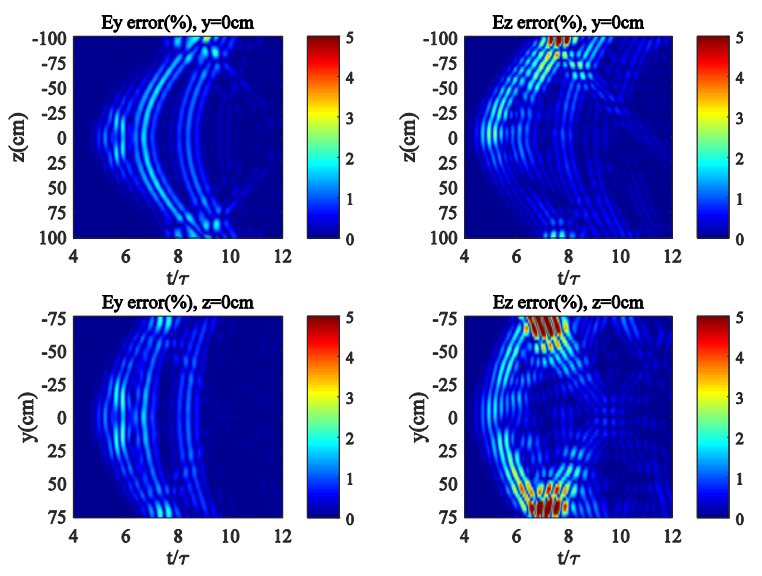

Fig. 9-b The error values of Ey and Ez at the plane cuts $y=0$ and $z=0$ resulting from the NFNF transformation: the NF data is measured at $x_{\text {meas }}=30$ $\mathrm{cm}$ and transformed to calculate the field at $50 \mathrm{~cm}$ from the AUT

chamber of dimensions $4 \mathrm{~m} \times 5 \mathrm{~m} \times 3 \mathrm{~m}$. We measure the tangential near-field components Ey and Ez while moving the probe respecting a regular spacing $\Delta \mathrm{y}=\Delta \mathrm{z}=3 \mathrm{~cm}$ between measurement points over the planar surface $\left(-60 \mathrm{~cm} \leq \mathrm{y}_{\text {meas }} \leq\right.$ $60 \mathrm{~cm}$ and $\left.-60 \mathrm{~cm} \leq z_{\text {meas }} \leq 60 \mathrm{~cm}\right)$ at $\mathrm{x}_{\text {meas }}=10 \mathrm{~cm}$ in front of the antenna. For our measurement investigations we have used the wideband probe "En-Probe EFS-105" [22]. This probe is composed of a small dipole (dimensions $6.6 \mathrm{~mm} \times 6.6 \mathrm{~mm}$ ) connected to the base unit through a fiber optic link and the base unit is connected to the measuring VNA through a short cable. This probe is dedicated to NF measurement covering the frequency band $(5 \mathrm{MHz}-3 \mathrm{GHz})$. The probe performances can be extended to $3.5 \mathrm{GHz}$ with slight measurement sensitivity degradation in the frequency band $(3 \mathrm{GHz}-3.5$ $\mathrm{GHz}$ ).

The antenna NF measurement is carried out in the frequency band $(0.3 \mathrm{GHz}-3.5 \mathrm{GHz})$ using a Vector Network Analyzer (Agilent ENA 5071b). Thereafter the measured frequency-domain NF complex data (amplitude and phase) are Fourier transformed to set the TD NF of the Vivaldi antenna when excited by the pulse given in Fig. 2. In Fig. 10, we compare the measured TD NF at the point $\left(\mathrm{x}_{\text {meas }}=10 \mathrm{~cm}\right.$, $\mathrm{y}_{\text {meas }}$ $\left.=0, \mathrm{z}_{\text {meas }}=0\right)$ with the one obtained from the CST MWS. The Ey component (co-polar) fits well the CST results. However, the Ez component (cross-polar) shows some discrepancies.
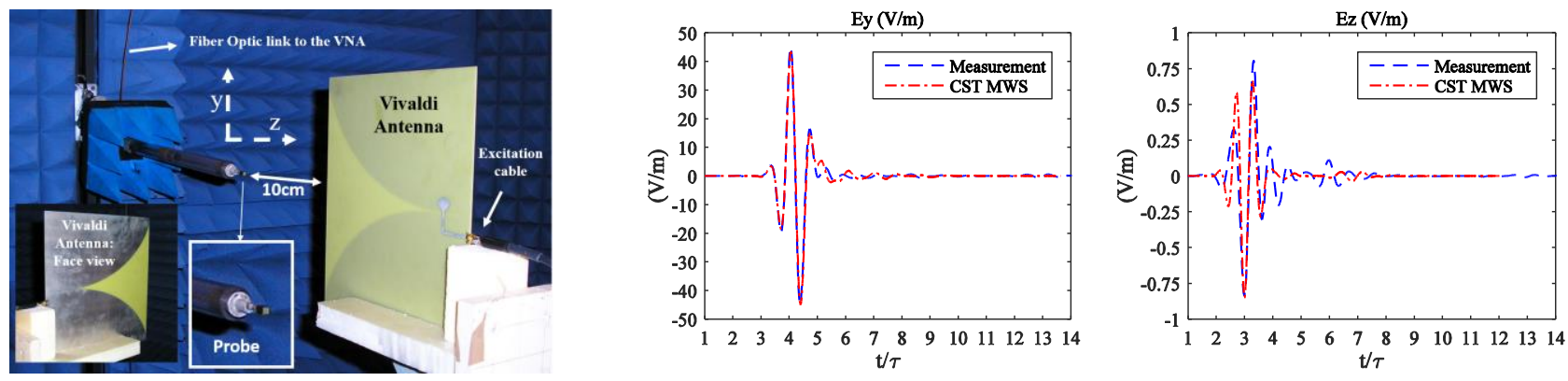

Fig. 10. (left) The Supelec planar measurement setup used for NF antenna measurement. The Vivaldi antenna is placed at $10 \mathrm{~cm}$ from the measuring probe (Enprobe EFS 105). The probe displacements (translation in y and z directions) are controlled by automated process. (right) The Vivaldi antenna transient radiated field (Ey (left) and Ez (right)) in the boresight direction is presented and compared with the CST MWS results after the calibration procedure (normalization). 

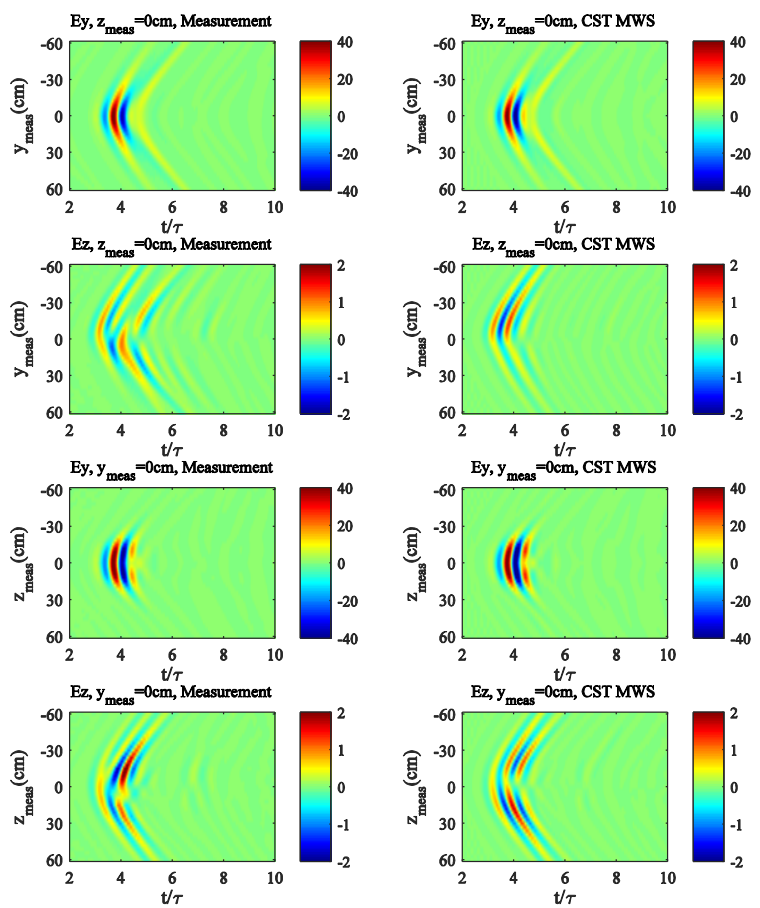

Fig. 11. The comparison between the measured Vivaldi near-field (Ey (V/m) and $\mathrm{Ez}(\mathrm{v} / \mathrm{m}))$ at the distance $\mathrm{x}_{\text {meas }}=10 \mathrm{~cm}$ from the Vivaldi antenna with the CST MWS results for the plane cuts $\mathrm{y}_{\text {meas }}=0$ and $\mathrm{z}_{\text {meas }}=0$

The NF probe used in this measurement campaign is supposed to behave like a point source. For probe calibration procedure, we have normalized the measured NF magnitude (co-polar) in order to reach the CST MWS maximum NF level. This is performed at the principal direction $\left(\mathrm{x}_{\text {meas }}=10\right.$ $\mathrm{cm}$, $\mathrm{y}_{\text {meas }}=\mathrm{z}_{\text {meas }}=0$ ) and the normalization coefficient is applied to measured NF data (Ey and Ez) over the measurement surface.

In Figs. 11 we compare the measured NF at $x_{\text {meas }}=10 \mathrm{~cm}$ with the CST MWS NF data after the calibration step. The agreements are very satisfactory for Ey component meanwhile the cross-polarization (Ez) shows some differences compared with the CST results. This is due to many reasons: in part to the antenna fabrication accuracy, measurement positioning errors (alignment), cross-polarization of the probe is not well defined, probe sensitivity for low field levels....

Using the NFNF routine we transform the NF data measured at plane $\mathrm{X}_{\text {meas }}=10 \mathrm{~cm}$ to calculate the field at the spatial positions $\mathrm{A}(\mathrm{r}=2.44 \mathrm{~m}, \theta=\pi / 2, \varphi=0), \mathrm{B}(\mathrm{r}=2.44 \mathrm{~m}, \theta$ $=\pi / 2, \varphi=\pi / 6), \mathrm{C}(\mathrm{r}=2.44 \mathrm{~m}, \theta=\pi / 3, \varphi=0)$ and $\mathrm{D}(\mathrm{r}=2.44$ $\mathrm{m}, \theta=\pi / 6, \varphi=0)$. The reference antenna radiation patterns used for these comparisons have been measured at Supelec cylindrical NF measurement facility placed in an anechoic chamber of dimensions $6 \mathrm{~m} \times 7 \mathrm{~m} \times 8 \mathrm{~m}$. This measurement facility is presented in Fig. 12 and the E-field is measured using the same probe as the planar NF range (En-Probe EFS$105)$ at the plane cuts $\theta=\pi / 2$ and $\varphi=0$. For our comparison, we consider the CST NF data $\left(\mathrm{x}_{\text {meas }}=10 \mathrm{~cm}\right)$ which are

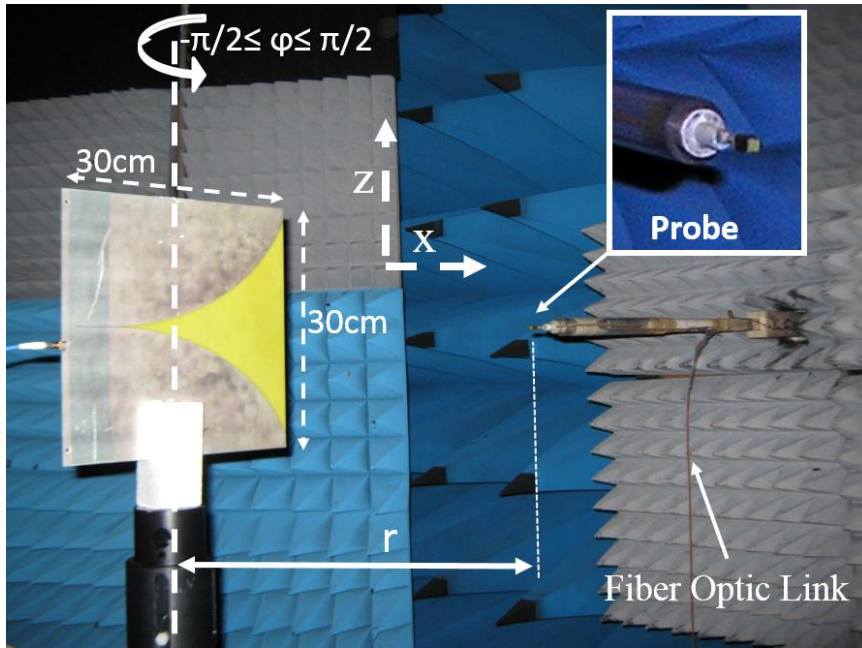

Fig. 12. The Supelec cylindrical near-field measurement facility used for our experimental validation. The AUT is rotated following the angle $-\pi / 2 \leq \varphi \leq$ $\pi / 2$. We use the same probe as the planar near-field facility (En-probe EFS $105)$.

transformed to reach the spatial positions A, B, C and D. These comparisons are carried out for the Ey components (copolar) and are presented in Figs. 13. As it is seen, good agreements are noticed between the measurement results. The NFNF transformation yields satisfactory results when using $\mathrm{NF}$ data measured at $10 \mathrm{~cm}$ from the AUT and transformed in order to calculate the transient response at the positions A, B, C. The differences observed for the position D are due to the NF measurement surface truncation error. The CST MWS NF collected at $10 \mathrm{~cm}$ is also transformed to calculate the field at the positions A, B, C and D. This has been done in order to verify that our calibration procedure stay correct and no additional calibration step is needed to compensate for the probe spatial response (the probe acts actually as a point source).

The NFNF transformation allows calculating Ex, Ey and Ez components in the half space $\mathrm{x} \geq \mathrm{x}_{\text {meas }}$ in front of the AUT using the tangential components measured at a given distance $\mathrm{x}_{\text {meas. }}$ Indeed, using Vivaldi antenna transient NF measured in the planar NF facility at $x_{\text {meas }}=10 \mathrm{~cm}$ from the AUT we perform NFNF transformation to set the transient field over the planar surface at $x=40 \mathrm{~cm}(-60 \mathrm{~cm} \leq y \leq 60 \mathrm{~cm}$, and -60 $\mathrm{cm} \leq z<60 \mathrm{~cm})$. These are compared with the CST MWS results at the plane cuts ( $x=40 \mathrm{~cm}, y=0,-60 \mathrm{~cm} \leq z \leq 60 \mathrm{~cm})$ and $(x=40 \mathrm{~cm},-60 \mathrm{~cm} \leq y \leq 60 \mathrm{~cm}, z=0)$. As is it seen in Figs. 14, the NFNF transformation results fit well the simulated Ey component (co-polar). The normal component Ex for the plane cut $y=0$ agrees well with the simulated results. However, low level fields (cross-pol) present many discrepancies compared with the CST MWS results. Generally, the results of NFNF and NFFF transformations present some difficulties to set accurately the low-level crosspolarization field since the cross-polarized NF component is difficult to measure accurately with the EFS-105 probe (Fig. 10). 

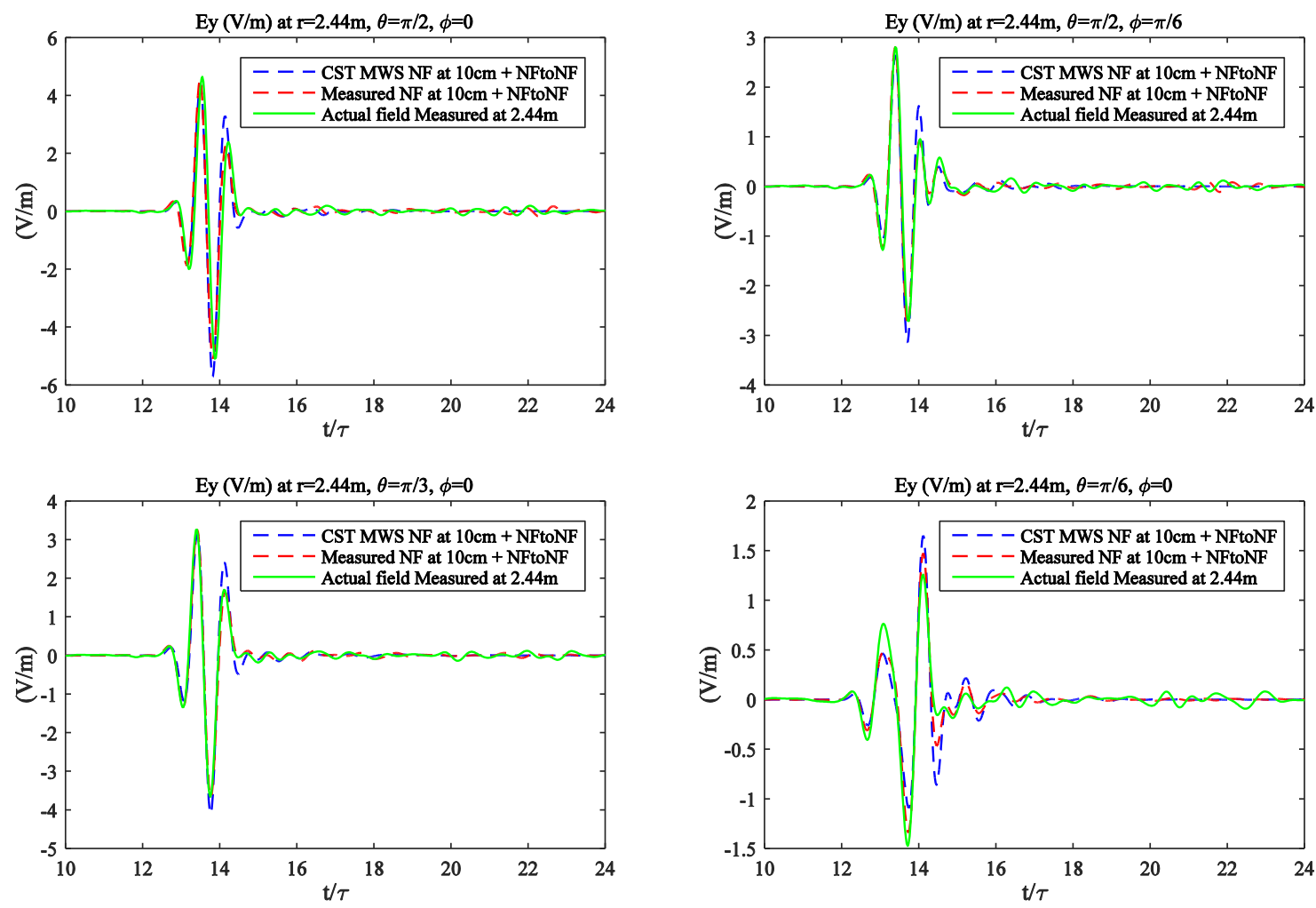

Fig. 13. The NFNF results at the spatial points $\mathrm{A}(\mathrm{r}=2.44 \mathrm{~m}, \theta=\pi / 2, \varphi=0), \mathrm{B}(\mathrm{r}=2.44 \mathrm{~m}, \theta=\pi / 2, \varphi=\pi / 6), \mathrm{C}(\mathrm{r}=2.44 \mathrm{~m}, \theta=\pi / 3, \varphi=0)$ and $\mathrm{D}(\mathrm{r}=2.44 \mathrm{~m}, \theta=$ $\pi / 6, \varphi=0$ ) compared with the CST MWS and the directly measured field in the cylindrical facility.
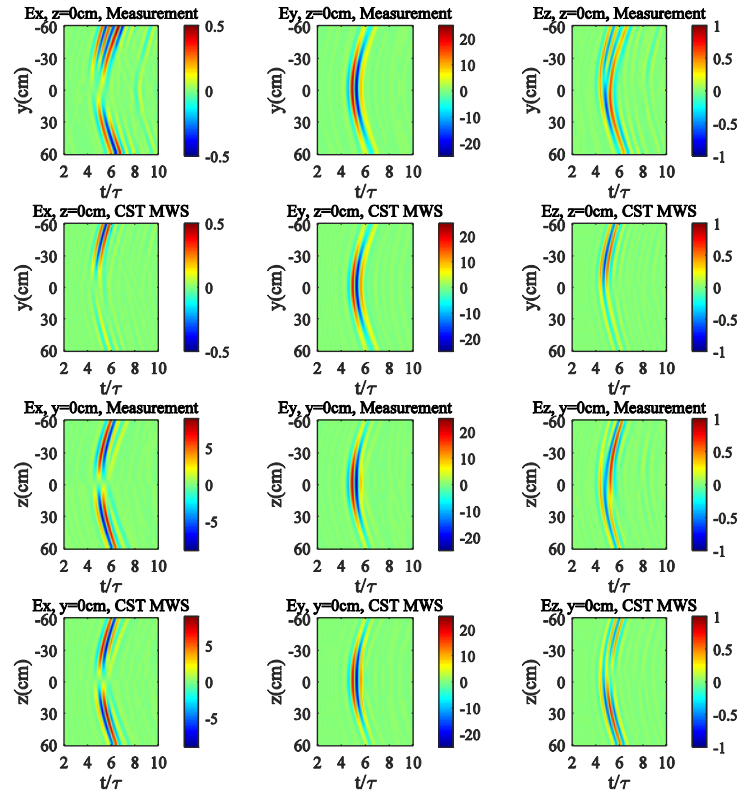

Fig. 14. The NFNF results at $x=40 \mathrm{~cm}$ compared with the CST MWS results at the plane cuts $\mathrm{y}=0$ and $\mathrm{z}=0 . \mathrm{NF}$ data $(\mathrm{Ey}$ and $\mathrm{Ez})$ have been measured at $\mathrm{x}_{\text {meas }}=10 \mathrm{~cm}$ from the AUT and transformed to reach the planar surface $\mathrm{x}=$ $40 \mathrm{~cm}$. The comparison comprises Ex, Ey and Ez transient field components.

Finally, using the NF data measured at $\mathrm{x}_{\text {meas }}=10 \mathrm{~cm}$ in the planar NF facility we perform NFFF transformation to calculate the transient far-field over the plane cut $(\theta=\pi / 2,-\pi / 2$ $\leq \varphi \leq \pi / 2$ ). The NFFF results are Fourier transformed to determine the AUT radiation pattern in the frequency domain. These are compared in Fig. 15 with the actual FF obtained from the CST MWS at the frequencies $1.5 \mathrm{GHz}, 2 \mathrm{GHz}$ and $2.5 \mathrm{GHz}$. The comparison includes also the TD NFFF transformation results of the CST MWS NF data collected at $\mathrm{x}_{\text {meas }}=10 \mathrm{~cm}$ from the AUT and the measured field in the cylindrical measurement facility at $2.44 \mathrm{~m}$ from the AUT. From Fig. 15, a satisfactory agreement is noticed between the TD (time-domain) NFFF and the CST MWS FF results for the angular region -48 deg. $\leq \varphi \leq 48$ degree. Beyond this area $(\varphi \leq-$ $48 \mathrm{deg}$. and $\varphi \geq 48 \mathrm{deg}$.) the differences between the different curves are due to the measurement surface truncation.

\section{CONCLUSION}

This paper has presented the experimental validation of Time-Domain (TD) Near-Field to Near-Field (NFNF) and Near-Field to Far-Field (NFFF) transformation for antenna transient characterization. Based on the Green's function representation we have derived NFNF and NFFF transformation calculation schemes which have been validated using electromagnetic simulation software and experimental measurement data. The studied Vivaldi antenna radiated transient field has been measured and near-field to near / farfield transformations have resulted in a good accuracy compared with the CST MWS simulated transient field. The NFNF transformation can also be used to determine the normal components of the radiated transient field. In addition, the frequency domain comparison have shown a satisfactory 

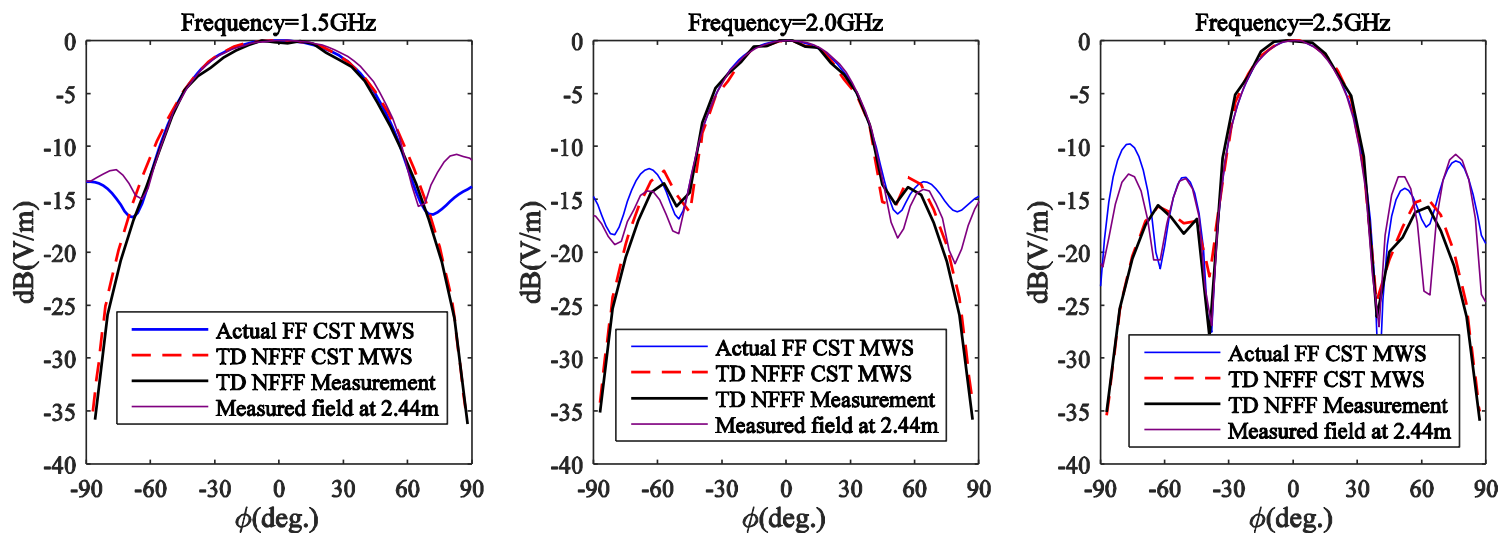

Fig. 15. The frequency domain results comparison. The FF issued from measured NF data $\left(\mathrm{x}_{\text {meas }}=10 \mathrm{~cm}\right)$ using the planar facility is compared with the CST MWS directly calculated FF for the frequencies $1.5 \mathrm{GHz}, 2 \mathrm{GHz}$, and $2.5 \mathrm{GHz}$ for the FF cut plane $\theta=\pi / 2$. The NFFF transformation results are Fourier transformed to calculate the frequency domain FF. The FF validity area is about $\pm 48 \mathrm{deg}$.

accuracy for far-field calculation.

\section{REFERENCES}

[1] D.J. Daniels, Surface Penetrating Radar, The IEE press, London, 1996.

[2] De Jongh, R. V., Ligthart, L. P., Kaploun, I. V., \& Schukin, A. D. (1999). Design and analysis of new GPR antenna concepts. TIJDSCHRIFT-NEDERLANDS ELEKTRONICA, 64, 26-32

[3] A.S. Turk, "Ultra-wideband TEM horn design antenna design for ground-penetrating impulse radar systems", Microwave and Optical Technology Letters, 41

[4] Yarovoy, A.G.; Schukin, A.D.; Kaploun, I.V.; Ligthart, L.P., "The dielectric wedge antenna," Antennas and Propagation, IEEE Transactions on , vol.50, no.10, pp.1460,1472, Oct 2002

[5] Yarovoy, A.G.; Qiu, W.; Yang, B.; Aubry, P.J., "Reconstruction of the Field Radiated by GPR Antenna into Ground," Antennas and Propagation, 2007. EuCAP 2007. The Second European Conference on, vol., no., pp.1,6, 11-16 Nov. 2007

[6] T. B. Hansen and A. D. Yaghjian "Plane-wave theory of time-domain fields, near-field scanning applications" IEEE Press, New York (1999)

[7] De Jough, R.V.; Hajian, M.; Ligthart, L.P., "Antenna time-domain measurement techniques," Antennas and Propagation Magazine, IEEE , vol.39, no.5, pp.7,11, Oct 1997

[8] Yaghjian, A.D., "An overview of near-field antenna measurements," Antennas and Propagation, IEEE Transactions on , vol.34, no.1, pp.30,45, Jan 1986

[9] Blech, M. D., Leibfritz, M. M., Hellinger, R., Geier, D., Maier, F. A., Pietsch, A. M., and Eibert, T. F.: A time domain spherical near-field measurement facility for UWB antennas employing a hardware gating technique, Adv. Radio Sci., 8, 243-250, 2010.

[10] Serhir, M.; Picard, D.; Jouvie, F.; Guinvarc'h, R.; Ribiere-Tharaud, N., "Development of pulsed antennas measurement facility: Near field antennas measurement in time domain," Antenna Technology and Applied Electromagnetics (ANTEM), 2012 15th International Symposium on , vol., no., pp.1,4, 25-28 June 2012

[11] Jinhwan, K.; De, A.; Sarkar, T. K.; Hongsik, M.; Weixin, Z.; SalazarPalma, M., IFree Space Radiation Pattern Reconstruction from NonAnechoic Measurements Using an Impulse Response of the Environment," Antennas and Propagation, IEEE Transactions on, Vol. 60, No. 2, pp.821\{831, 2012.

[12] R. Rammal, M. Lalande, E. Martinod, et al., "Far-Field Reconstruction from Transient Near-Field Measurement Using Cylindrical Modal Development," International Journal of Antennas and Propagation, vol. 2009, Article ID 798473, 7 pages, 2009.

[13] Andrieu, J.; Nouvet, S.; Bertrand, V.; Beillard, B.; Jecko, B., "Transient characterization of a novel ultrawide-band antenna: the scissors antenna," Antennas and Propagation, IEEE Transactions on , vol.53, no.4, pp.1254,1261, April 2005

[14] Levitas, B.; Drozdov, M.; Naidionova, I.; Jefremov, S.; Malyshev, S.; Chizh, A., "UWB system for time-domain near-field antenna measurement," Microwave Conference (EuMC), 2013 European , vol., no., pp.388,391, 6-10 Oct. 2013

[15] Ravelo B., Liu Y. and Ben Hadj Slama J., "Time-domain nearfield/near-field transform with PWS operations", The European Physical Journal Applied Physics, 53, 30701, 2011.

[16] Hansen, T.B.; Yaghjian, A.D., "Planar near-field scanning in the time domain .1. Formulation," Antennas and Propagation, IEEE Transactions on , vol.42, no.9, pp.1280,1291, Sep 1994.

[17] Hansen, T.B.; Yaghjian, A.D., "Planar near-field scanning in the time domain .2. Sampling theorems and computation schemes," Antennas and Propagation, IEEE Transactions on, vol.42, no.9, pp.1292,1300, Sep 1994.

[18] A. Yarovoy, R. de Jongh and L. Ligthart, "Ultrawideband sensor for Electromagnetic Field Measurement in Time Domain," Electronics Letter, Vol. 36, No.20, 28th Sept. 2000

[19] Bucci, O.M.; D'Elia, G.; Migliore, D., "Near-field far-field transformation in time domain from optimal plane-polar samples," Antennas and Propagation, IEEE Transactions on , vol.46, no.7, pp.1084,1088, Jul 1998

[20] CST Microwave studio 2014 user's guide.

[21] Martini, E.; Breinbjerg, O.; Maci, S., "Reduction of Truncation Errors in Planar Near-Field Aperture Antenna Measurements Using the Gerchberg-Papoulis Algorithm," Antennas and Propagation, IEEE Transactions on, vol.56, no.11, pp.3485-3493, Nov. 2008.

[22] http://www.enprobe.de/products_FO-Antennas.htm. 